\title{
Temporal Integration and Duration Tuning in the Dorsal Zone of Cat Auditory Cortex
}

\author{
Jufang He, ${ }^{1,2,3}$ Tsutomu Hashikawa, ${ }^{1}$ Hisayuki Ojima, ${ }^{4}$ and Yohsuke Kinouchi ${ }^{2}$ \\ ${ }^{1}$ Laboratory for Brain Structure and Function, Frontier Research Program, The Institute of Physical and Chemical \\ Research (RIKEN), Wako, Saitama 351-01, Japan, ${ }^{2}$ Department of Electrical and Electronic Engineering, The University of \\ Tokushima, Tokushima 770, Japan, ${ }^{3}$ Advanced Research Laboratory, Hitachi, Hatoyama, Saitama 350-03, Japan, and \\ ${ }^{4}$ First Department of Anatomy, Toho University School of Medicine, Tokyo 143, Japan
}

\begin{abstract}
The present study examined auditory cortical neurons, the responses of which depended on the duration of noise bursts. We recorded from 150 neurons with response latencies exceeding $30 \mathrm{msec}$ and from 28 neurons with OFF responses to auditory stimuli in the dorsal zone of cat auditory cortex. Of 150 long-latency neurons, 132 displayed some form of duration selectivity. Seventy-eight were classified as selective for long durations. Among the long-duration-selective neurons, 30 responded only to noise burst stimuli with durations longer than a minimal threshold and were classified further as duration threshold neurons. Of 132 duration-selective neurons, 41 responded selectively to noise bursts of short duration; 13 showed maximal responses to noise bursts of a particular duration and could be regarded as duration-tuned neurons. OFF-response neurons included ones that were long-durationselective, duration-tuned, and nonduration-selective.
\end{abstract}

Duration tuning has been described previously only at the midbrain level in amphibians and bats. The present finding of sensitivity to sound duration in at least one region of cat auditory cortex indicates that this form of neural tuning may be important for hearing in all vertebrates, and for processing of sound at multiple levels in the auditory pathway. The duration tuning in the cat auditory cortex was much broader, and the best duration was distributed over a wider range than in the bat inferior colliculus. We suggest that the duration selectivity of the long-latency neurons results from integration along the time domain of a stimulus during the latent period.

Key words: dorsal auditory cortex; long-latency response; duration-selective neuron; temporal summation; temporal suppression; duration threshold neuron; OFF response; cat
The duration of a sound is an important component of acoustic information. Animals perceive the same sounds differently depending on the duration (Repp et al., 1978). Neurons tuned to sound duration were first found in the midbrain of the frog by Potter (1965) and Feng et al. (1990), and later in the bat inferior colliculus by Pinheiro et al. (1991) and by Casseday et al. (1994). The finding of duration-tuned neurons suggests that there may be a place code for sound duration (Casseday et al., 1994).

Calford and colleagues found that neurons in the dorsal nucleus (MGd) of the medial geniculate body (MGB) respond to pure tones with latencies that exceed the duration of activity in the ventral nucleus of the MGB (MGv) by tens of milliseconds (Calford and Webster, 1981; Calford, 1983; Lennartz and Weinberger, 1992). The MGd projects to the dorsal zone (DZ), the primary auditory cortex (AI), the anterior auditory field (AAF), and other regions of auditory cortex (Winer et al., 1977; Andersen et al., 1980). Some have considered the DZ to be a part of AI and AAF (Woolsey, 1964; Andersen et al., 1980), whereas others have suggested that DZ is functionally and anatomically distinct with its

\footnotetext{
Received Oct. 15, 1996; revised Jan. 2, 1997; accepted Jan. 22, 1997.

This study was supported by the Frontier Research Program, The Institute of Physical and Chemical Research. We thank E. G. Jones for continuous support and encouragement during the course of the study and two unnamed reviewers for much help in improving this manuscript. We also thank M. N. Semple, S. Lehky, C. N. Honda, S. Tanaka, and K. Cheng for comments on an early draft of this manuscript, and N. Suga and M. Merzenich for fruitful discussions.

Correspondence should be addressed to Jufang He, Advanced Research Laboratory, Hitachi, Hatoyama, Saitama 350-03, Japan.

Copyright (C) 1997 Society for Neuroscience 0270-6474/97/172615-11\$05.00/0
}

major input from the MGd (Middlebrooks and Zook, 1983; He et al., 1994).

Physiologically, neurons in the DZ differ in frequency specificity from AI, showing broad and/or multipeaked tuning properties and binaural responses (Middlebrooks and Zook, 1983; Sutter and Schreiner, 1991). In the present study, we demonstrate that many neurons in the DZ respond with long latency and are selective for sound duration. It is possible that the DZ may be involved in more complex aspects of sound processing in terms of analyses in the frequency domain and in the time domain.

Some of the present results have been reported in abstract form (He et al., 1994, 1996).

\section{MATERIALS AND METHODS}

Animal preparation. Eleven healthy cats of both sexes served as subjects, weighing $2.4-3.8 \mathrm{~kg}$ with clean external ears and normal auditory thresholds estimated from cortical unit responses. Because it took a long time to identify the DZ at the beginning of the study, we performed chronic experiments on five animals $(110,113,114,115$, and 116). During the latter half of the study, we were able to identify the target region in a sufficiently short time, and thus shifted to acute experiments (6 cats: 120, $123,125,137,138$, and 139).

In the chronic experiments, anesthesia was initially induced with pentobarbital sodium (40 mg/kg Nembutal, i.p., Abbott Laboratories, Irving, TX) and maintained by supplemental doses $(5-10 \mathrm{mg} / \mathrm{kg} / \mathrm{hr}$, i.p.) during the surgical preparation. A midline incision was made in the scalp, and a craniotomy was performed over the left and/or right ectosylvian gyri, especially in their dorsal regions. The craniotomy opening was usually smaller than $8.0 \times 8.0 \mathrm{~mm}^{2}$. The dura mater was left intact. A brass block to be used for head fixation was attached to the frontal top of the skull with stainless steel screws and acrylic resin. A stainless steel chamber 18 
$\mathrm{mm}$ in diameter was installed over the skull opening for later unit recordings. Inside the chamber on the skull above the craniotomy, we drilled two small holes in an anteroposterior orientation to act as reference marks for the systematic identification of the auditory cortex in the later recording sessions.

Recordings were made once a week on each chronic animal under sterile conditions. Anesthesia was induced with pentobarbital sodium (40 $\mathrm{mg} / \mathrm{kg}$, i.p.) and supplemented as needed during the recording sessions (1-4 mg/kg/hr, i.p). A single injection of atropine sulfate $(0.05 \mathrm{mg} / \mathrm{kg}, \mathrm{s.c}$. $)$ was given 15 min before anesthesia. The head of the animal was fixed by a brass block cemented to the skull. Ear bars were not used. Body temperature was maintained between $37.5^{\circ} \mathrm{C}$ and $38.5^{\circ} \mathrm{C}$ using a feedback-controlled heating pad. Connective tissue over the dura was removed before recording. Animals were given an antibiotic (penicillin, Tomiyama Chemical, $100 \mathrm{mg} / \mathrm{kg}$, i.m.) at the beginning and end of each recording session.

In the acute experiments, anesthesia for surgery was the same as that used for chronic experiments. Anesthesia was then switched to ketamine during the recording session as needed $(5 \mathrm{mg} / \mathrm{kg} / \mathrm{hr}$, i.m. $)$. Head fixation during the recording session was the same as in the chronic experiments. These procedures have been evaluated and approved by the Laboratory Animal Care Committee in The Institute of Physical and Chemical Research.

Acoustic stimuli. Acoustic stimuli were generated digitally by an MALab system (Kaiser Instruments, Irvine, CA) that was controlled by a Macintosh computer (Semple and Kitzes, 1993; Spitzer and Semple, 1993). Fifty millisecond tone pips (10 msec rise/fall time) were used to identify the AI and AAF. Noise bursts (white noise), varying in duration between 20 and $500 \mathrm{msec}$, and 100-msec-long pure tones were used to examine neuronal responses in the DZ. Stimuli were repeated at long intervals of 1.2-3.0 sec to prevent habituation. The rise/fall times of those stimuli were $10 \mathrm{msec}$ for four experiments and $5 \mathrm{msec}$ for seven experiments. The auditory stimuli were delivered by two headphones and conducted to each ear by silicon tubes. Before recording, tympanic sound pressure level (SPL, expressed in $\mathrm{dB}$ re $20 \mathrm{mPa}$ ) was calibrated for a frequency range of $100 \mathrm{~Hz}$ to $40 \mathrm{kHz}$ under computer control using a previously calibrated probe tube and a condenser microphone (Brüel and Kjær, Copenhagen, Denmark; $1 / 4$ inch). The calibration data were stored in a computer file for use in controlling the attenuator to obtain desired SPLs (Semple and Kitzes, 1993). The cat was placed in a double-walled soundproof room (Industrial Acoustic, Bronx, NY), and its head was held using the brass block.

Recording. Platinum or tungsten microelectrodes with impedances of 9-12 M $\Omega$ (Frederick Haer \& Co., Brunswick, ME) penetrated the dura and were further advanced by a stepping-motor microdrive that was controlled from outside the soundproof room. Electrode penetrations were made approximately orthogonal to the cortical surface. After being amplified and filtered, neural signals were led through a window discriminator and passed to an oscilloscope and an audio monitor. The times of spike occurrence relative to stimulus delivery were stored on the same computer that controlled stimulus delivery, which also automatically created raster displays and peristimulus time histograms (PSTHs) of the responses.

To identify AI and AAF, we most often recorded spikes from cell clusters (2-5 cells) rather than single cells in order to map a large cortical area in a reasonable period of time (Ojima et al., 1991; He, 1997). However, we specifically isolated single units in the primary area of interest, i.e., the DZ. The electrode picked up responses of a few neurons simultaneously. The spike shape of a single unit was then discriminated from the responses of the neuronal cluster using an amplitude and time window discriminator in the software package of the MALab system.

The coordinates of the manipulator were reset to its original values by reference to the two marks on the skull at the beginning of each recording session. The exposed dura was covered with paraffin to prevent it from drying and to reduce movements of the brain caused by pulsation and respiration. A total of 20-50 penetrations and an average of eight sessions were made in each hemisphere.

After the last recording session of each chronic experiment, 0.05-0.10 $\mathrm{ml}$ of $2 \%$ wheat germ agglutinin-horseradish peroxidase (WGA-HRP) in $0.05 \mathrm{M}$ Tris buffer ( $\mathrm{pH}$ 8.6) was injected by pressure in the DZ, where single-unit recordings were made to visualize subsequently retrogradely labeled cells in the auditory fields and the MGB (J. He, T. Hashikawa, and E. G. Jones, unpublished observations). The animals were deeply anesthetized with sodium pentobarbital and perfused transcardially with $0.9 \%$ saline followed by a mixture of $0.4 \%$ paraformaldehyde and $2.5 \%$ glutaraldehyde in $0.1 \mathrm{M}$ phosphate buffer ( $\mathrm{pH} 7.3$ ) $48 \mathrm{hr}$ after the injection of WGA-HRP. The brains were dissected free and stored overnight in 0.1 M phosphate buffer containing $30 \%$ sucrose. The brainstems were cut transversally, and the auditory cortices were sectioned in an oblique horizontal plane approximately perpendicular to the posterior ectosylvian sulcus and the middle and posterior ectosylvian gyri on a freezing microtome (Imig and Reale, 1980). Retrogradely labeled cells in auditory fields and the MGB in every fourth section $(50 \mu \mathrm{m})$ were visualized by the tetramethylbenzidine reaction (Mesulam, 1976; He et al., 1994; He, 1997). The injection site was used to determine the penetration coordinates.

Data analysis. We observed three firing patterns: phasic, phasic burst (PB), and sustained (for classification, see Gooler and Feng, 1992). The number of spikes was counted over the full phasic or PB firing period. The sustained firing neurons continued to fire during or slightly longer than the stimulus duration. In the few cases of sustained discharge, the number of spikes was counted over their period of sustained firing (maximally to $300 \mathrm{msec}$ ). Although the spontaneous activity of neurons in the DZ under anesthetized conditions in this study was low, the average spontaneous firing rate over repeated trials during the $100 \mathrm{msec}$ immediately before the stimulus onset was subtracted from spike number or normalized discharges (in which maximal response equals 1.0).

For the purpose of observing the latency distribution of all recorded neurons as shown in Figures 1 and 2, the minimal latency was defined as the period between stimulus onset and the time when the neuron showed a response obviously greater than its spontaneous firing in the PSTH. However, the latency shown in other figures was precisely calculated by averaging the first spikes of all effective, repeated trials of a stimulus. The influence of spontaneous firing on the latency calculation was eliminated by restricting spikes in the calculation to a limited time period according to the firing pattern. The calculation was made using the software package of the MALab system.

All means in the text are expressed as mean \pm SD. Comparisons between response latencies and stimuli of different intensities were evaluated with Student's $t$ tests. Results were considered significant at the 95\% confidence level $(p<0.05)$.

\section{RESULTS}

\section{Dorsal zone of the cat auditory cortex}

The tonotopic organization of AI and AAF of the cat has been described previously (Woolsey, 1961; Merzenich et al., 1975; Reale and Imig, 1980). In the present study, multiple-electrode penetrations provided partial maps of the spatial distribution of best frequencies (BFs), enabling us to identify AI based on its tonotopic organization. One example of such a frequency map is shown in Figure 1. The numbers with decimal points indicate the BFs (in kilohertz) of single- or multiunits located at the indicated sites. In AI, neurons with high BF were located anteriorly, and neurons of low BF were located posteriorly. The situation was the reverse for neurons in AAF. Most neurons in these two fields had minimal response latencies shorter than $20 \mathrm{msec}$ and were sharply tuned to their BFs. The response latencies to noise bursts are indicated as integers in the figure.

When we shifted the recording electrode from AI to the DZ, a large population of long-latency neurons was revealed, and tuning curves became broad and/or multipeaked, which confirmed previous findings of such tunings in DZ by Middlebrooks and Zook (1983) and by Sutter and Schreiner (1991). Neurons recorded in the DZ showed a variety of minimal latencies ranging from 10 to 230 msec. The map of minimal latencies, however, was not systematically organized in any subject examined.

\section{Long-latency neurons}

One hundred and fifty neurons in the DZ with response latencies longer than $30 \mathrm{msec}$ were defined as long-latency neurons, and the distribution of their minimal latencies is shown in Figure 2. The latencies plotted in Figure 2 were obtained from responses to noise bursts that varied in duration from 10 to $300 \mathrm{msec}$. The 
Animal: \#116
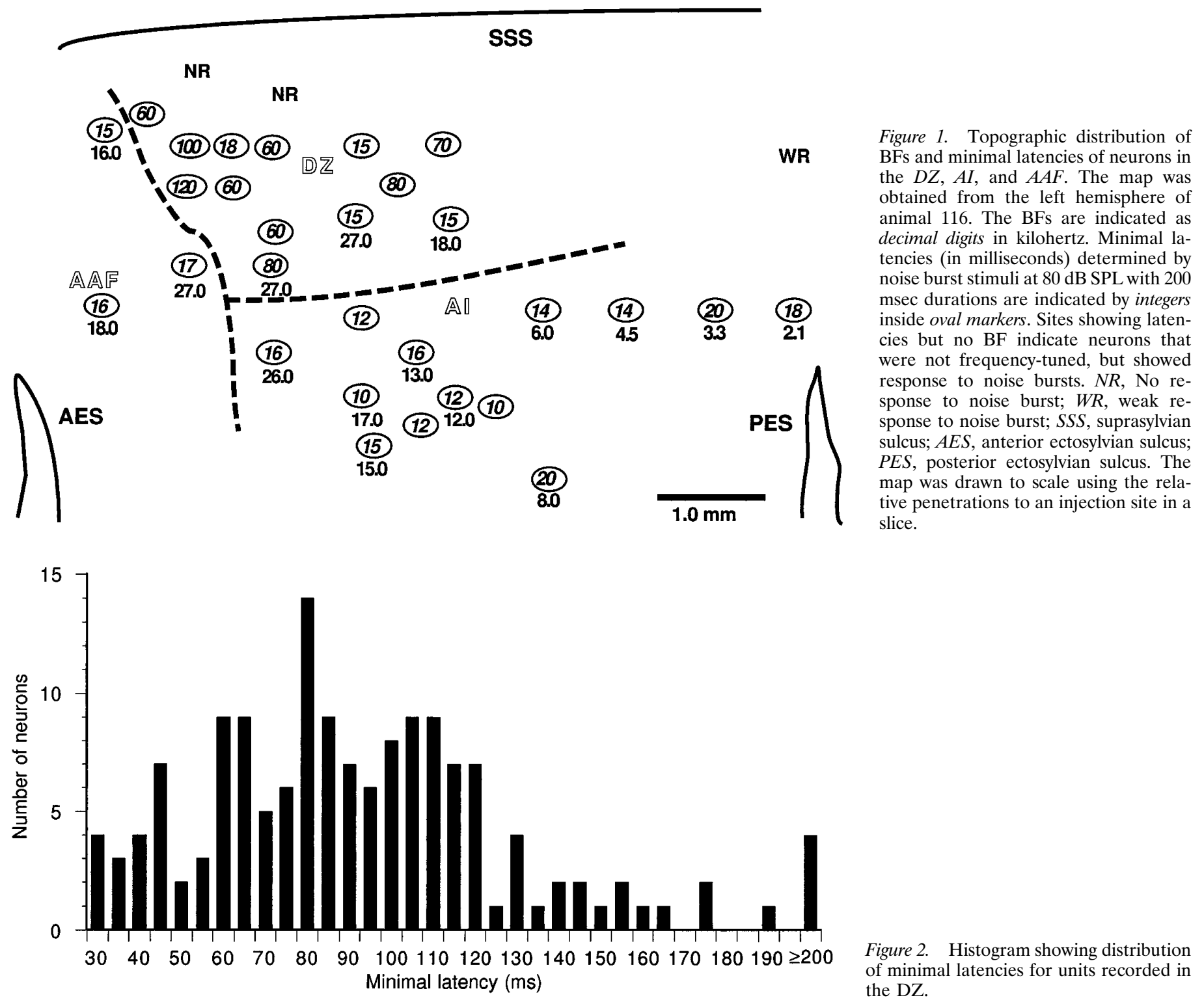

Figure 2. Histogram showing distribution of minimal latencies for units recorded in the DZ.

maximum of the minimal latencies was $230 \mathrm{msec}$, and the minimal latencies of $85 \%$ of neurons were distributed from 30 to $120 \mathrm{msec}$. Of 150 long-latency neurons, 125 (83\%) showed PB or phasic temporal discharge patterns, and $25(17 \%)$ showed sustained discharge patterns. Spontaneous activity of most of these neurons was very low.

In addition to measuring latencies, we determined the monotonicity of the responses of these neurons as a function of sound intensity. Because many neurons in the DZ show broad and/or multipeaked frequency-tuning properties, we tested the monotonicity of the long-latency neurons by using noise bursts of 200 msec duration instead of pure tones at their BFs. Most neurons (127 of 150) exhibited a monotonic rate/intensity function in that their responses progressively increased, eventually saturated, or declined only slightly as a function of stimulus intensity. We used the same criterion to discriminate nonmonotonic neurons from monotonic neurons as used by Phillips et al. (1994, 1995). Two stimulus intensities, 10-20 dB and 50-60 dB above the threshold, were used to evoke the neuronal responses. If spike counts evoked at the higher stimulus intensity were $<50 \%$ of those evoked at the lower stimulus intensity, then the neuron was classified as nonmonotonic.

We were able to record from long-latency neurons in animals anesthetized with either pentobarbital sodium or ketamine. Their response properties to stimuli of varied duration did not show obvious differences under the two forms of anesthesia. However, the average spontaneous firing rate increased to $4.60 \pm 3.67$ spikes/sec $(n=136)$ from $1.14 \pm 1.16$ spikes $/ \mathrm{sec}(n=42)$ after we shifted the anesthesia from pentobarbital sodium to ketamine. This result is consistent with that of Zurita et al. (1994), who showed an average spontaneous firing rate of 4.1 spikes/sec when using ketamine as the anesthetic, and 1.3 spikes/sec when using pentobarbital sodium anesthesia in the cat nonspecific auditory cortex.

An example of the responses to noise bursts of a long-latency neuron is shown in the raster display in Figure 3. The mean latencies of the first spikes evoked by noise stimuli are shown in the figure. The neuron responded to noise bursts of 70, 100, and 


\section{$114 \mathrm{r}-015$}

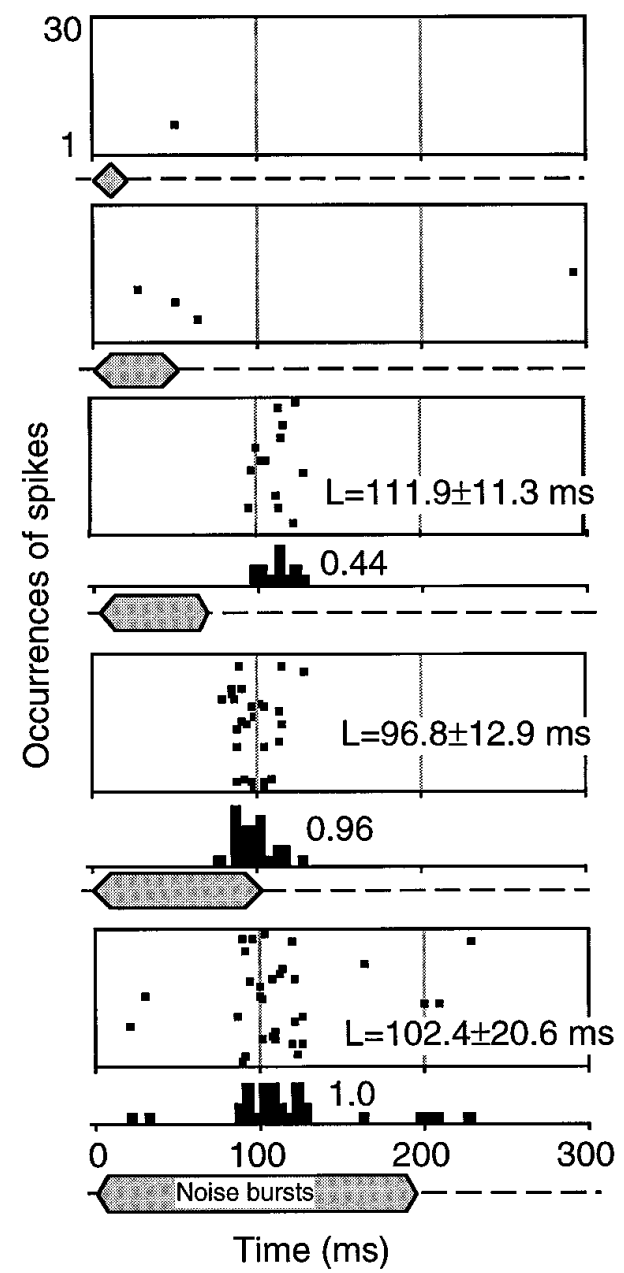

Figure 3. Responses of a long-latency neuron (114r-015). Raster displays (30 trials) show the times of occurrence of spikes elicited by noise bursts of varied duration ( $80 \mathrm{~dB}$ SPL). PSTHs for stimuli of 70, 100, and 200 msec durations are shown below the raster displays. Normalized discharges (number of spikes divided by the maximal number of spikes) are shown by numbers over the PSTHs. Duration of noise bursts is indicated below the raster displays or PSTHs. The response latencies $(L)$, calculated by averaging the first spikes of all effective repeated trials of a stimulus, are shown with their SDs. The influence of spontaneous firing on the latency calculation was eliminated by restricting the spikes used in the calculation to a limited time period according to the firing pattern. The calculation was made using the software package of the MALab system.

200 msec duration at latencies of 96-111 msec, whereas it showed weak responses to pure tones of $8.0-14 \mathrm{kHz}$ at similar latencies (data not shown). The intensities of the noise bursts and pure tones were the same ( $80 \mathrm{~dB}$ SPL). The number of spikes evoked on each trial of effective stimuli (both noise bursts and pure tones) varied from 0 to 3 , and the spikes were distributed primarily over a range of 90-130 msec after stimulus onset.

The neuron in Figure 3 showed an increasing number of spikes as the duration of a noise burst was increased from 50 to $100 \mathrm{msec}$ and reached its maximum response to a noise burst of $100 \mathrm{msec}$ duration. The responses in terms of number of spikes and timing of spikes remained unchanged when we prolonged the duration of the noise burst further from 100 to $200 \mathrm{msec}$. Among the 150 long-latency neurons, 78 showed increasing responses of this type when we prolonged the duration of the noise burst stimulus, as illustrated by the three additional examples shown in Figure 4. Fifty-four long-latency neurons showed decreasing numbers of discharges as the stimulus duration was lengthened, and are described in a separate section below. The remaining 18 neurons showed complicated response properties as a function of stimulus duration or were not duration-dependent and were excluded from further study. There was no obvious difference in latency properties among different response-type neurons (data not shown in the figures).

\section{Long-duration-selective neurons}

The 78 neurons whose responses increased when we prolonged the stimulus duration were classified as long-duration-selective neurons. Many of these neurons required certain minimal stimulus durations. For example, the neuron in Figure 3 did not respond to noise bursts shorter than $50 \mathrm{msec}$, but did respond to noise bursts longer than $50 \mathrm{msec}$. Operationally, we consider that this neuron has a duration threshold of $\sim 50 \mathrm{msec}$. Applying this criterion, 30 neurons were further classified as duration threshold (long-duration-selective) neurons. Of the three neurons shown in Figure 4, those in Figure 4, $A$ and $B$, had duration thresholds of approximately 100 and $50 \mathrm{msec}$, respectively. Neurons that responded to noise bursts of increasing duration with increasing numbers of spikes, but did not have a duration threshold, were called nonduration threshold (long-duration-selective) neurons. For example, the neuron in Figure $4 C$ had a minimal latency of $\sim 70 \mathrm{msec}$ and showed increasing spike numbers for noise bursts of longer duration, but responded to all durations tested.

The neuron in Figure $4 A$ had a latency of $146 \mathrm{msec}$, responded to noise bursts of $300 \mathrm{msec}$ duration, and showed increasing responses to stimulus intensities above $70 \mathrm{~dB}$ SPL. The duration threshold of the neuron did not change when we varied the stimulus intensity from 60 to $70 \mathrm{~dB}$ SPL. A common feature of long-duration-selective neurons with phasic or PB discharge patterns was that responses in terms of number of spikes and timing of spikes remained unchanged when the stimulus duration was prolonged beyond their phasic or PB discharge latency. Two examples of this feature are shown in Figures 3 and $4 B$.

To demonstrate the classification of duration threshold and nonduration threshold neurons, the number of spikes recorded as a function of the duration of the stimulus for each of 11 sampled neurons is shown in Figure 5, $A$ and $B$. Curves in Figure $5 A$ showed a steep slope over only a short period, and the slope started from a critical stimulus duration, whereas curves in Figure $5 B$ showed increasing spike numbers from the beginning. Neurons showing spike number/stimulus duration curves like those in Figure $5 A$ were classified as duration threshold neurons, and neurons showing curves like those in Figure $5 B$ were classified as nonduration threshold neurons.

\section{Responses to stimuli of varied intensity}

Responses of two long-duration-selective neurons to noise bursts of varied intensity and varied duration are shown in Figure 6 . The neuron in Figure $6 A$ had a minimal latency of $\sim 45 \mathrm{msec}$, showed responses only to noise bursts with durations longer than $30 \mathrm{msec}$, and was considered to have a duration threshold of $30 \mathrm{msec}$. This neuron responded to noise bursts with increasing numbers of spikes as their duration increased from 30 to $80 \mathrm{msec}$. As shown in the figure, the response latency of the neuron did not vary when the stimulus intensity was changed from 50 to $90 \mathrm{~dB}$ SPL. The neuron in Figure $6 B$ showed increasing spike numbers in response to noise bursts with durations up to $100 \mathrm{msec}$, but did not show a 


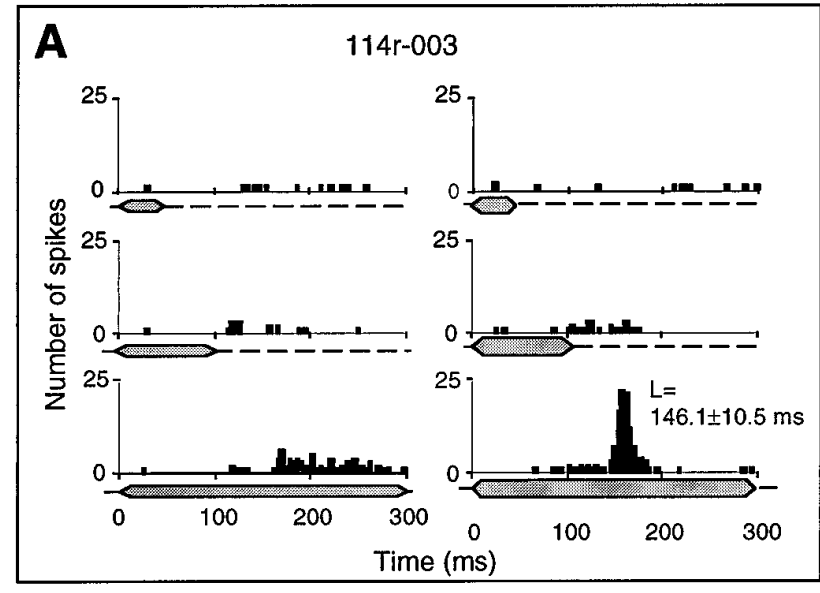

Stimulus: $60 \mathrm{~dB}$ SPL $70 \mathrm{~dB}$ SPL $80 \mathrm{~dB}$ SPL
B
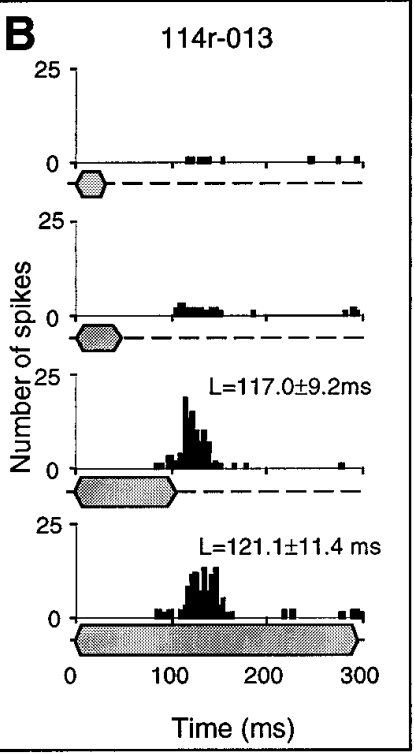

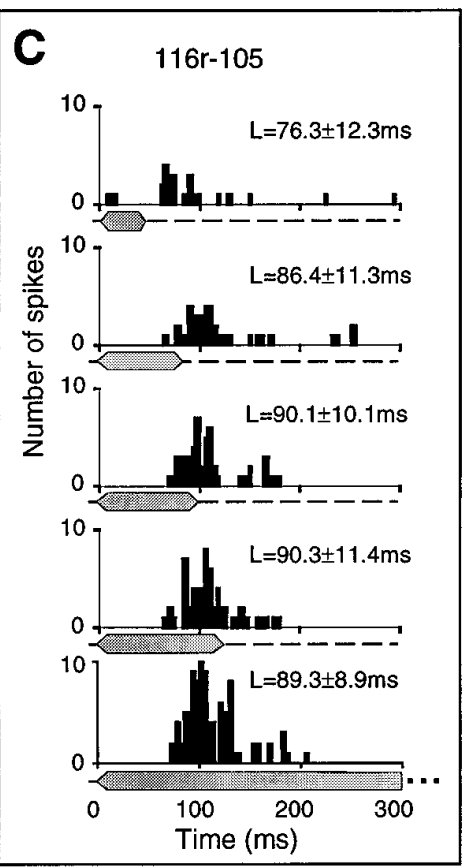

Figure 4. Responses of long-duration-selective neurons in the DZ to noise bursts of varied duration and varied sound intensity. The duration of noise bursts is shown below the PSTHs. A thicker duration marker indicates a stimulus of higher intensity. A, Discharges of neuron $114 r$-003 were summed over 50 trials. The left column shows the responses to stimuli of $60 \mathrm{~dB}$ SPL, and the right column shows the responses to those of $70 \mathrm{~dB}$ SPL. The neuron was activated at a mean latency of $146 \mathrm{msec}$, but only when the stimulus lasted longer than $100 \mathrm{msec}$. $B$, Discharges of neuron $114 \mathrm{r}$ - 013 were summed over 30 trials. The neuron was activated with a mean latency of $\sim 120 \mathrm{msec}$ and showed no difference in spike number or minimal latency when presented with noise bursts of 100 or $200 \mathrm{msec}$ duration. $C$, Discharges of neuron 116r-105 were summed over 100 trials. Responses to noise bursts of 60, 80, 100, 120, and $400 \mathrm{msec}$ duration are shown in the PSTHs. The neuron was active with a mean latency of $\sim 76-90$ msec and showed increasing activity when the duration of the noise burst was prolonged up to $120 \mathrm{msec}$.

A

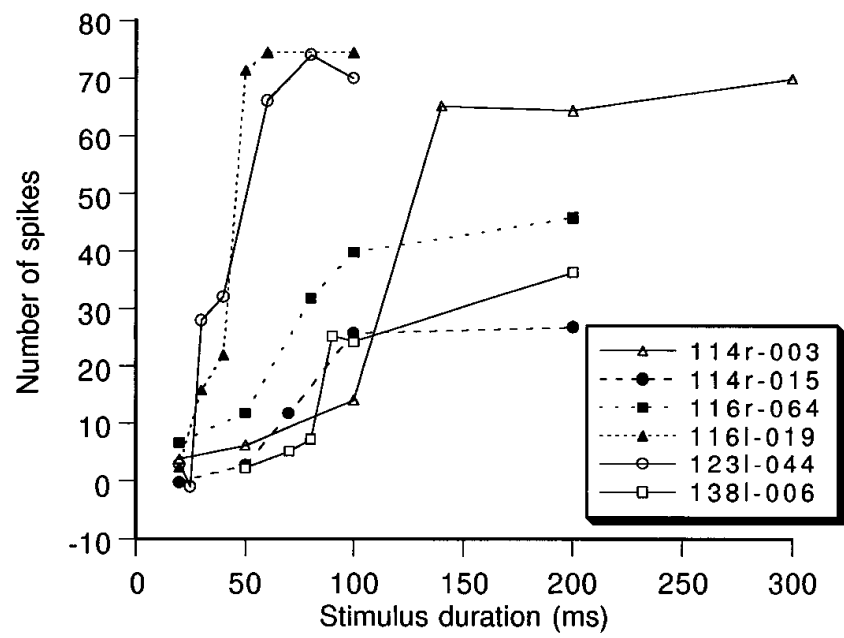

B

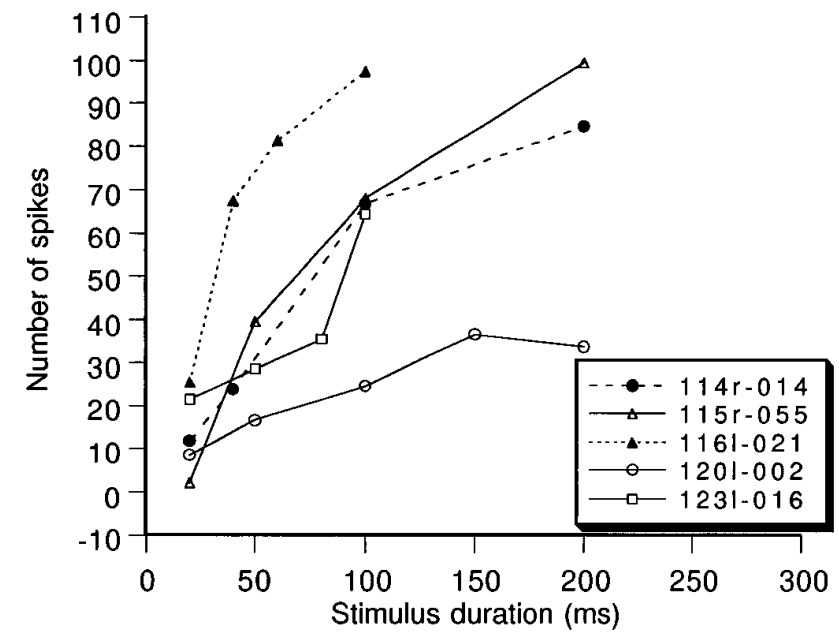

Figure 5. Number of spikes of long-duration-selective neurons elicited by noise burst stimuli as functions of stimulus duration. $A$, Duration threshold neurons $(n=6) ; B$, nonduration threshold neurons $(n=5)$. The number of spikes was summed over 30 trials. Data of neurons $114 r-003$, 116l-019, and 115 r- 055 were normalized to 30 trials from their original data, which were summed over 50,20 , and 50 trials, respectively.

clear duration threshold in its responses. The response latency of this neuron showed a small increase from 97.0 to $106.9 \mathrm{msec}$ ( $p=$ $0.057, n=4$ ) when the stimulus intensity was strengthened from 80 to $95 \mathrm{~dB}$ SPL. Because both of these neurons showed monotonically increasing spike numbers for stimuli of higher intensity, they were regarded as having monotonic responses to stimulus intensity.
Among 78 long-duration-selective neurons, 70 (90\%) showed monotonic functions to stimulus intensity and only $8(10 \%)$ showed nonmonotonic functions. A greater proportion of the remaining long-latency neurons (15 of 72 , or $21 \%$ ) showed nonmonotonic functions to stimulus intensity compared with longduration-selective neurons.

Responses of duration threshold neurons depended more on 

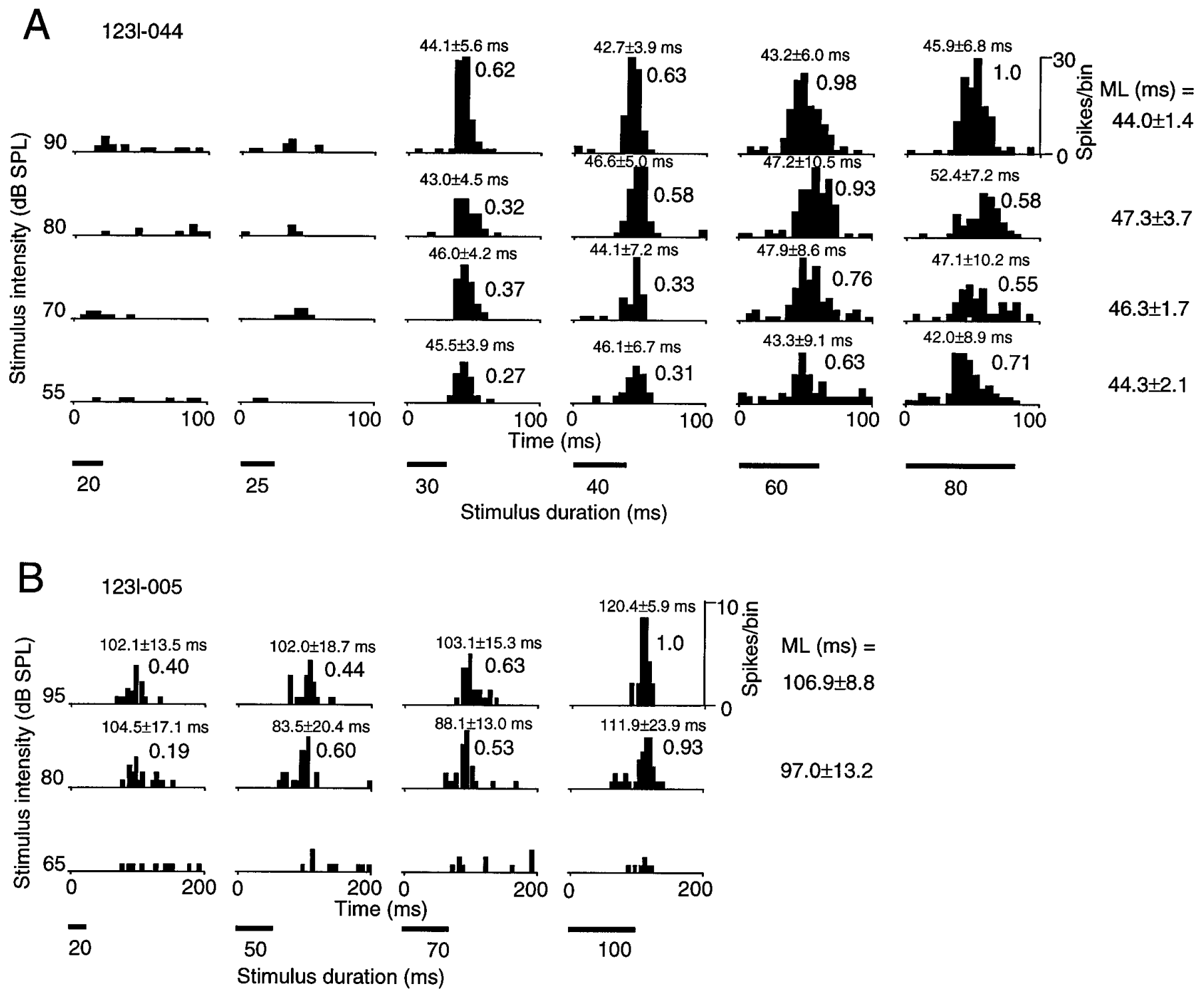

Figure 6. PSTHs showing responses of two long-duration-selective neurons, 1231-044 $(A)$ and 1231-005 (B), to noise bursts of varied duration and varied intensity. Duration of noise bursts is shown by the length of the black bars under the PSTHs. Number of spikes per bin (bin width, 5 msec) shown in top right corner applies in each figure to all PSTHs. The PSTHs of both neurons were summed over 30 trials. Decimal digits over the PSTHs indicate the normalized responses. The response latency for each stimulus was calculated in the same manner shown in the legend to Figure 3 and is shown above each PSTH. The mean latency $(M L)$, shown to the right of each row, is the average over stimuli of the same intensity and varying durations.

the stimulus duration than on the stimulus intensity when the stimulus duration was shorter than the duration thresholds. The neuron in Figure $6 A$, which responded monotonically to stimulus intensity, gave a greater response to a $60 \mathrm{msec}$ duration stimulus at $90 \mathrm{~dB}$ SPL (0.98) than to an $80 \mathrm{msec}$ duration stimulus at $55 \mathrm{~dB}$ SPL (0.72), and a greater response to a $30 \mathrm{msec}$ duration stimulus at $90 \mathrm{~dB}$ SPL (0.63) than to a $40 \mathrm{msec}$ duration stimulus at $55 \mathrm{~dB}$ SPL (0.33). The neuron responded to a $30 \mathrm{msec}$ duration stimulus at $55 \mathrm{~dB}$ SPL but did not respond to a $25 \mathrm{msec}$ duration stimulus at a much greater intensity, $90 \mathrm{~dB}$ SPL. That is, the response of the neuron depended more on the stimulus duration than on its intensity when the duration was shorter than $30 \mathrm{msec}$. The situation was different for nonduration threshold neurons. The dependence of the response on duration or intensity for the neuron shown in Figure $6 B$ could not be clearly categorized.

\section{Short-duration-selective and duration-tuned neurons}

Fifty-four long-latency neurons showed decreasing numbers of discharges as the stimulus duration was lengthened. Three examples are shown in Figure 7. The neuron in Figure $7 A$ showed a good response to noise bursts of $50 \mathrm{msec}$ duration and a decreasing number of spikes when the duration of the stimulus was prolonged to 100 and $200 \mathrm{msec}$. In other words, the neuron could be regarded as a short-duration-selective neuron. The neuron in Figure $7 B$ was similarly classified as a short-duration-selective neuron. As shown in the figure, the latency of this neuron became longer when the stimulus intensity was increased. The neuron in Figure $7 C$, however, showed an increasing number of spikes when we prolonged the duration of the stimulus from 20 to $50 \mathrm{msec}$, and then a decreasing number of spikes if we prolonged the duration of the stimulus further. The neuron responded best to stimuli with 
A
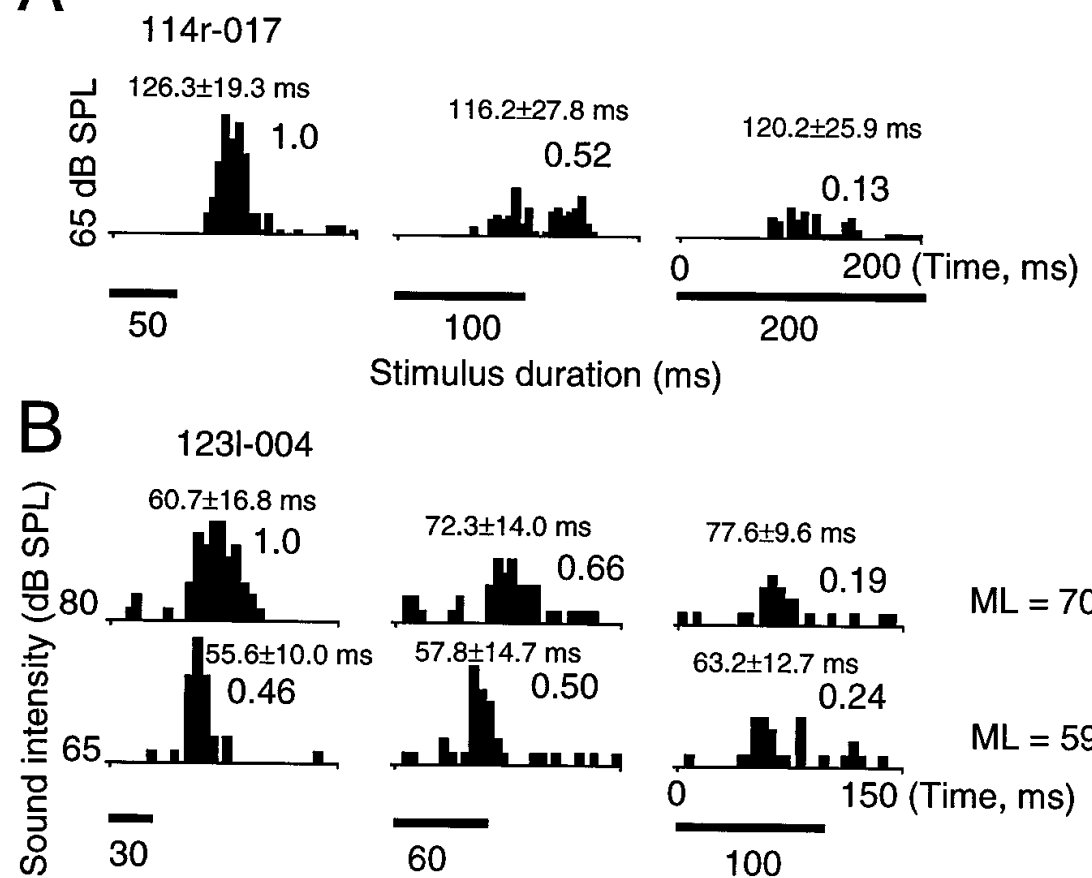

Stimulus duration (ms)

$77.6 \pm 9.6 \mathrm{~ms}$

ML $=70.3 \pm 8.6 \mathrm{~ms}$

$63.2 \pm 12.7 \mathrm{~ms}$

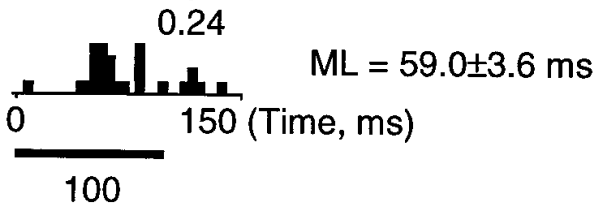

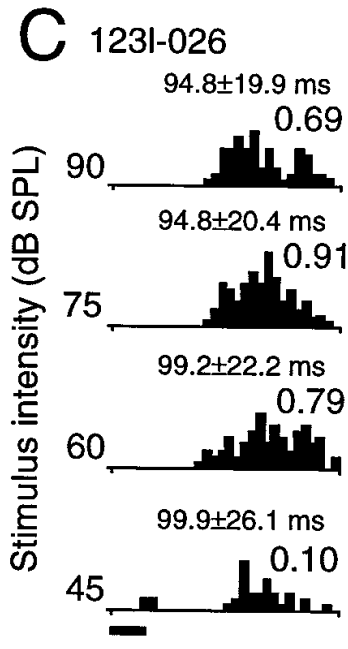

20
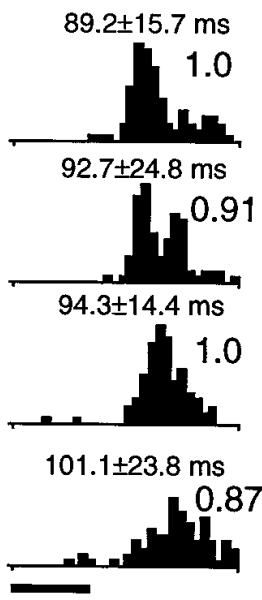

50

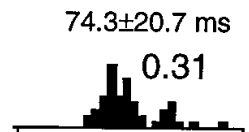

$74.0 \pm 24.8 \mathrm{~ms}$

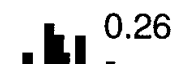

$91.5 \pm 33.4 \mathrm{~ms}$

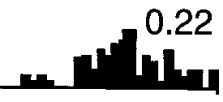

$98.9+33.6 \mathrm{~ms}$

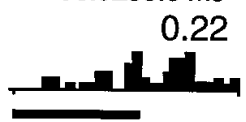

80

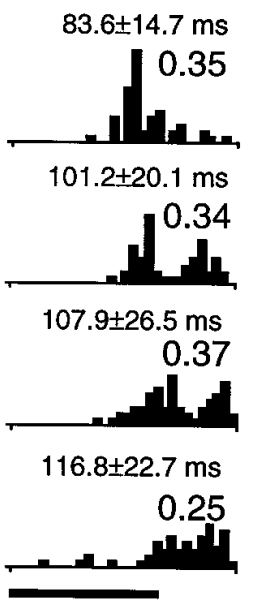

100

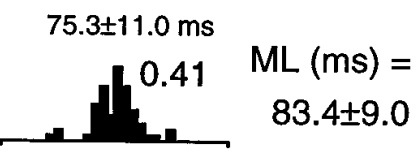

$90.2 \pm 10.2$
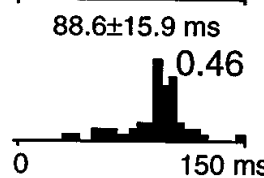

Time (ms)

$96.0 \pm 8.0$

$104.2 \pm 8.5$

Stimulus duration (ms)

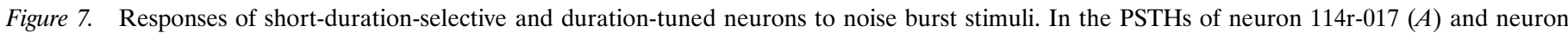

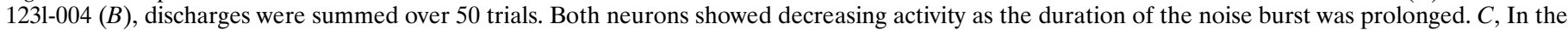
PSTHs, discharges were summed over 30 trials. The same conventions as in Figure 6 are applied.

a duration of $50 \mathrm{msec}$ and could be regarded as a duration-tuned neuron. In contrast to the neurons in Figures $6 B$ and $7 B$, the response latency of the neuron in Figure $7 C$ showed a decreasing function as the stimulus intensity was increased $(p<0.05)$.

Forty-one neurons were classified as short-duration-selective neurons, and 15 were classified as duration-tuned neurons. The remaining neurons showed complicated discharge patterns that could not be categorized readily in terms of duration selectivity and were excluded from further study. Figure 8 shows dischargerate/stimulus-duration functions of 11 examples of short-durationselective and duration-tuned neurons. Five short-durationselective neurons are shown in Figure $8 A$, and six duration-tuned neurons are shown in Figure $8 B$. The short-duration-selective neurons showed short-pass property, and the duration-tuned neurons showed band-pass property in their spike-number/stimulusduration functions.

Based on a criterion of two-thirds of the maximal discharge, the average width of the pass windows of the short-duration-selective neurons was $65 \mathrm{msec}(n=33 ; 8$ neurons were excluded from the calculation), with an SD of $30 \mathrm{msec}$. The average width of the pass windows of duration-tuned neurons was $92 \mathrm{msec}$, with an SD of 30 msec. Windows started from an average of $35 \mathrm{msec}$ (range, 15-60 msec; $n=11 ; 4$ neurons were excluded) and terminated at an average of $127 \mathrm{msec}$ (range, 69-172 msec). 

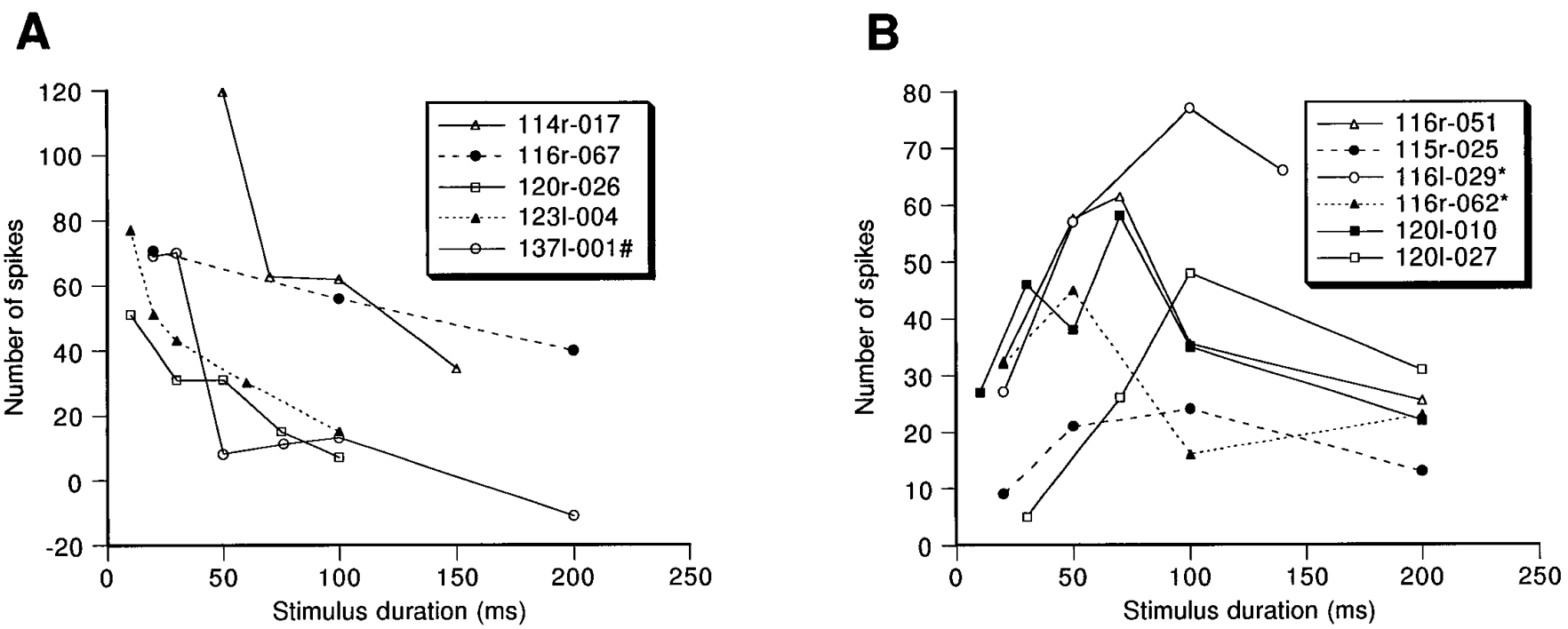

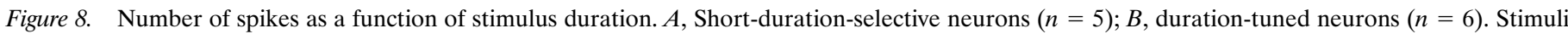
were noise bursts. \#, Summation of 20 trials; *, summation of 100 trials. All other neurons summed over 50 trials.

\section{OFF-response neurons}

Of 28 OFF-response neurons recorded from the DZ of the auditory cortex, 17 were classified as long-duration-selective neurons, 7 as duration-tuned neurons, and the remaining 4 as nonduration-specific neurons. Figure 9 shows two examples of OFF-response neurons. The neuron in Figure $9 A$ was a longduration-selective neuron and showed increasing discharges to stimuli of longer duration. The neuron in Figure $9 B$ was a duration-tuned neuron and showed (1) no response to noise bursts of durations shorter than $100 \mathrm{msec}$, (2) a maximal response to a noise burst of $200 \mathrm{msec}$ duration, and (3) small responses to noise bursts of durations longer than $500 \mathrm{msec}$.

Functions of spike-number/stimulus-duration for six longduration-selective neurons and seven duration-tuned neurons are shown in Figure 10.

\section{DISCUSSION}

The present study examined the effect of varying stimulus duration on neuronal response properties, including total spike count and latency in the DZ of the cat auditory cortex. The neurons exhibited different degrees of selectivity for noise bursts of varied duration, and long-duration-selective, short-duration-selective, and duration-tuned neurons could be recognized.

Duration-tuned neurons have been reported in the central thalamus and midbrain of the frog where short-pass, long-pass, band-pass, and band-suppression response characteristics were demonstrated (Potter, 1965; Feng et al., 1990, 1991; Gooler and Feng, 1992). These neurons in the bullfrog had response latencies between 8.5 and $150 \mathrm{msec}$ ( 85 of 93 neurons were $>20 \mathrm{msec}$ ) (Potter, 1965). The variability of the first spike latency for each neuron was small and comparable to our results as shown over the PSTHs of sampled neurons in the figures. Casseday et al. (1994) found short-pass and band-pass duration-tuned neurons in the inferior colliculus but not in the cochlear nucleus of the bat, suggesting that duration tuning is computed in the inferior colliculus. Long-pass, short-pass, and band-pass duration-tuned neurons correspond to the long-duration-selective, short-durationselective, and duration-tuned neurons of the present report.

In their whole-cell patch-clamp study, Casseday et al. (1994) showed that the duration-tuned neurons in the bat inferior colliculus had OFF responses similar to those obtained in the present study. The duration tuning in the DZ of the cat auditory cortex appears to be broader than in the bat inferior colliculus, and the best durations were distributed over a wider time domain of up to $200 \mathrm{msec}$ compared with the bat (up to $75 \mathrm{msec}$ ) (Casseday et al., 1994).

In the present study, 17 of 28 OFF-response neurons showed duration selectivity. OFF responses have been frequently reported previously in the midbrain, the thalamus, and in the cortex in various species of mammals (Aitkin and Prain, 1974; Calford and Webster, 1981; Rhode and Smith, 1986; Bordi and LeDoux, 1994; Grothe, 1994). It has been suggested that the OFF response may be formed by a rebound after the offset of inhibitory input (Calford and Webster, 1981), and that duration-tuned OFF-response neurons may take advantage of this rebound to create a coincidence mechanism that in turn produces duration tuning (Casseday et al., 1994).

This coincidence mechanism seems to be applicable for OFFresponse neurons, but cannot explain the response properties of long-latency duration-selective neurons. An alternate mechanism of temporal integration is discussed below.

In the present study, we observed that the response latencies of different neurons showed different functions with respect to sound intensity. The response latency might be an information-bearing element as suggested by Middlebrooks and colleagues (Middlebrooks et al., 1994; Middlebrooks and Xu, 1996) in the auditory system, and by Gawne et al. (1996) in the visual system.

\section{Temporal integration}

Long-latency neurons showing increasing responses to stimuli of longer duration could be considered to be demonstrating temporal summation over the period of stimulus duration. Neurons that showed decreasing responses to stimuli of longer duration could be considered to be demonstrating temporal suppression during the later period of the stimulus. If a long stimulus consists of a sequence of many short time periods, then it is possible to place a value of a temporal integration weight for each period of the stimulus on the neuronal responses, based on the rate of change 

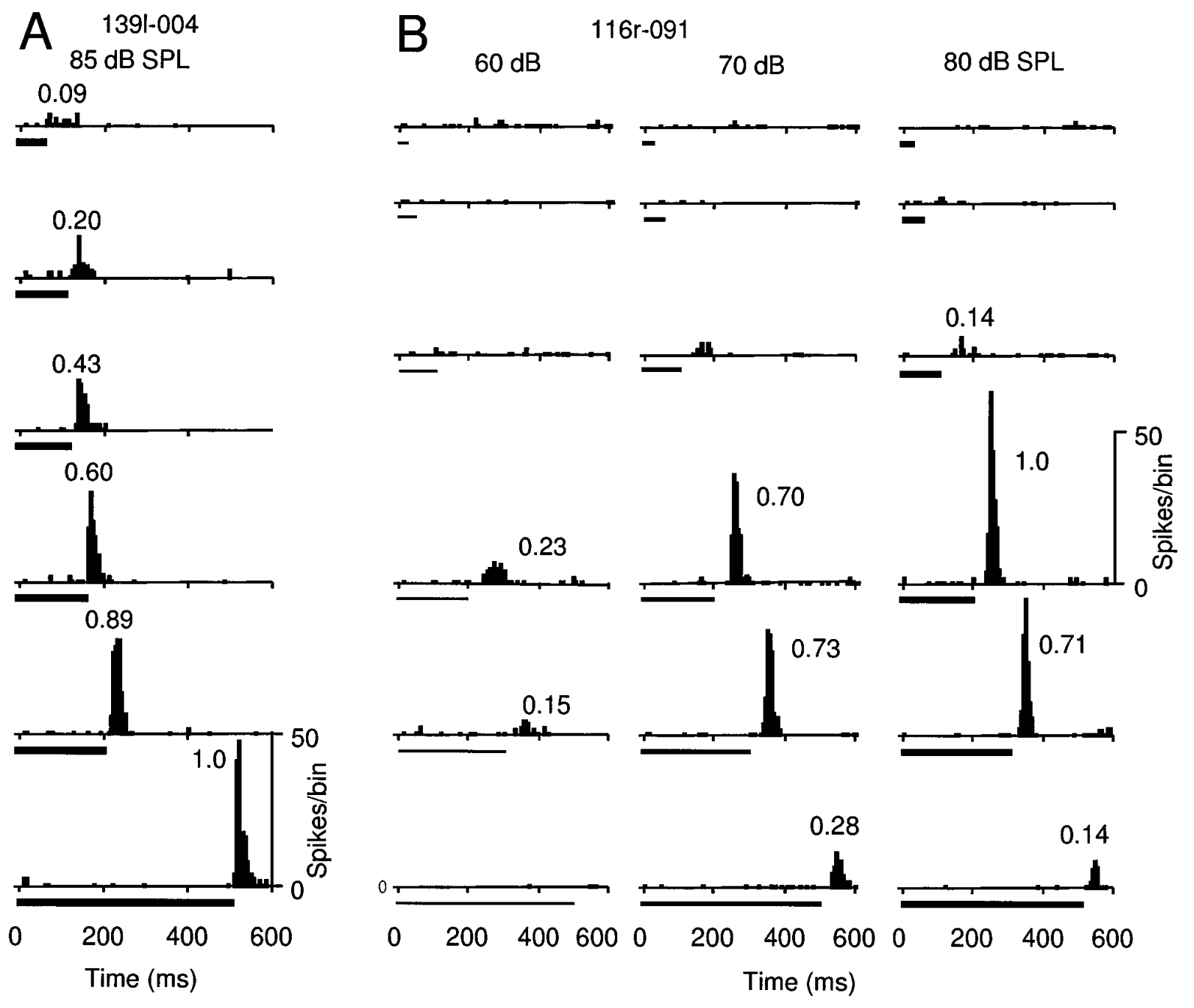

Figure 9. OFF-response neurons. $A$, Responses of a long-duration-selective neuron to noise bursts of constant sound intensity, but varied duration. $B$, Responses of a duration-tuned neuron to noise bursts of varied intensity and varied duration. Duration of noise bursts is shown by the length of the black bars under the PSTHs. Thicker bars indicate higher-intensity stimuli. Number of spikes per bin (bin width, $5 \mathrm{msec}$ ) shown on the right applies to all PSTHs. PSTHs of both neurons were summed over 30 trials.

of the responses as stimulus duration is prolonged. Temporal summation is associated with a positive temporal integration weight, whereas temporal suppression is associated with a negative integration weight.

Long-duration-selective neurons could be considered as having positive temporal integration weights over the effective period of the stimulus. Duration-tuned and short-duration-selective neurons might be considered as having a positive integration weight for the beginning period of a stimulus and a negative weight for the later period of the stimulus. It is possible that the shortduration-selective neurons are a subset of the duration-tuned neurons, which might be tuned to a shorter duration than those that were tested.

Munson (1947), Zwislocki (1960), and Moore et al. (1988) introduced the concept of the temporal window, i.e., a temporal integration period for summation of auditory information. Because each duration-threshold neuron showed rapidly increasing spike-number only when the stimulus duration was prolonged in a restricted time period, it could be considered as having a large positive value of temporal integration weight over a restricted time period of the stimulus. Each of the duration-threshold neu- rons may have a preferred time period for temporal information integration and indicate a particular time subsequent to the onset of a stimulus. Many such neurons together might represent the time axis of an auditory stimulus. The auditory system must have the ability to discriminate different time periods in a stimulus, and neurons with narrow time periods for temporal integration should provide more precise timing than neurons with wider time periods.

In other preliminary experiments, neuronal responses to noise bursts of varying durations have been examined in cat MGB, and many long-duration-selective neurons were found in the MGd, but so far no short-duration-selective or duration-tuned neurons have been found in the MGB (J. He, T. Hashikawa, and E. G. Jones, unpublished observations). Further investigation is necessary to clarify whether duration tuning first arises in the cortex of the cat or whether it reflects a process that has already taken place in the midbrain.

\section{Origin of long-latency responses in DZ}

Long-latency responses of greater than $30 \mathrm{msec}$ to pure-tone stimuli have been observed in more than $75 \%$ of the neurons in the MGd (Calford and Webster, 1981; Calford, 1983), and may 

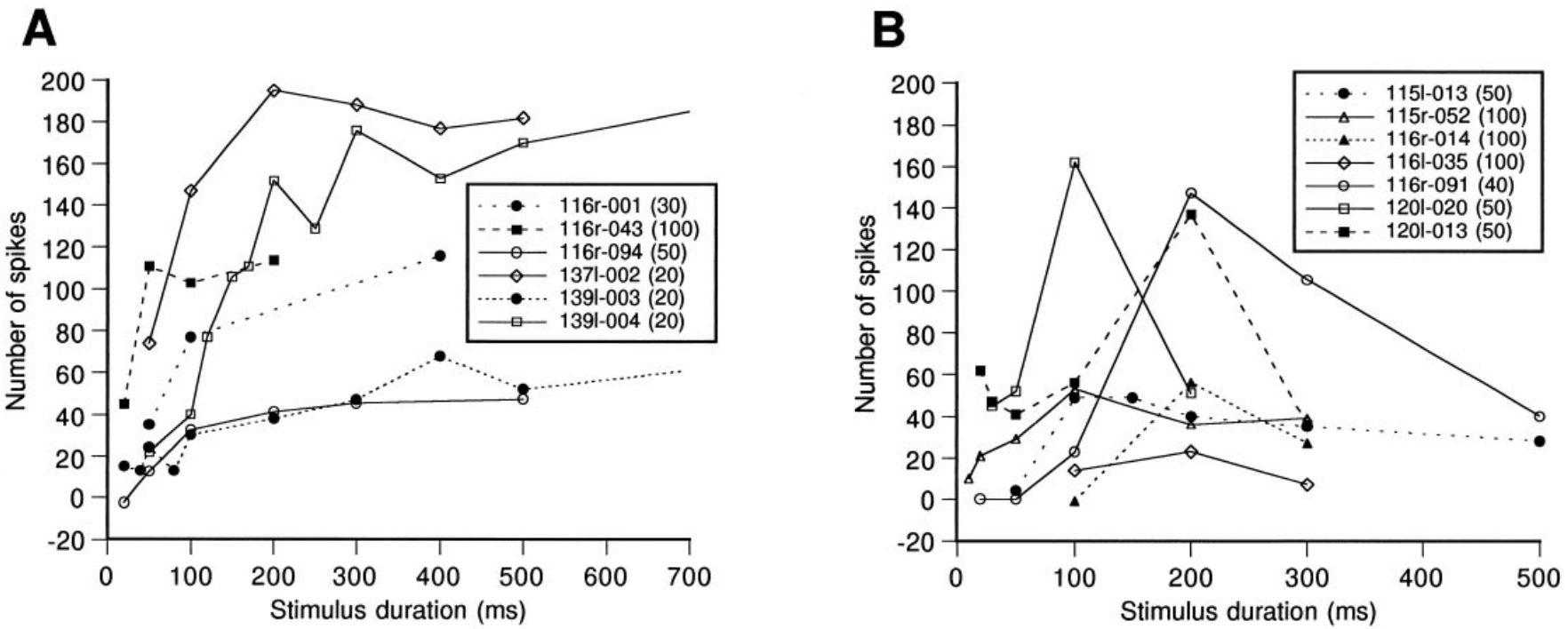

Figure 10. $A, B$, Number of spikes, which were elicited by noise bursts, as a function of stimulus duration for 13 OFF-response neurons. The integers in parentheses indicate the number of trials on which the spike counts were based.

depend in large part on the properties of the monosynaptic tectothalamic pathway, coupled with the membrane properties of the thalamic neurons ( $\mathrm{Hu}, 1995)$. The pathway running through the MGd appears to form a parallel system to that through the MGv in which neurons respond at much shorter latencies (Calford and Aitkin, 1983). Most of the long-latency neurons in the MGd show broad frequency tuning (Calford and Webster, 1981). Injection of a retrograde tracer, WGA-HRP, into the DZ, labeled many cells in MGd (He et al., 1994; J. He, T. Hashikawa, and E. G. Jones, unpublished observations), indicating that the DZ receives its thalamic input from the dorsal nucleus (Middlebrooks and Zook, 1983). The DZ cannot be regarded as a simple replication of the MGd, because projections from different frequency loci in AI converge on it (Ojima and He, 1994). This convergence suggests that further complicated processing of sound might take place in the DZ.

\section{Relation of duration sensitivity to temporal pattern processing}

Psychophysicists have measured temporal integration periods for detection of a wide variety of inputs in all sensory systems. From one psychophysical perspective, the temporal integration period is defined by the minimal duration of a specific, detected stimulus. From another perspective, which we emphasize here, the temporal integration period is the time epoch over which new inputs can add information to a perceived stimulus event (Dilollo, 1980; Green, 1985; Gerken et al., 1990) (for review, see Merzenich et al., 1993).

The temporal integration process is suggested to commence with the introduction of any new input, but can be interrupted and reset with the arrival of any novel subsequent stimuli (Merzenich et al., 1993). Backward maskers represent one class of interrupting stimuli (Hafter and Buell, 1990). Large variations in amplitude and/or frequency components of the stimulus may reset the integration. Short-latency ON responses to stimuli can be found in most MGB and AI neurons (Irvine, 1980; Calford and Webster, 1981; Langner and Schreiner, 1988), and these may form a basis for resetting.

In humans, speech perception is based on recognition of segmental units of various sizes, such as syllable phonemes, mor- phemes, and whole words (Goodman et al., 1994), involving the use of large variations in their amplitude and/or frequency components. We assume that the temporal pattern perception of animals is similar to human temporal information perception in a short time period of a segmental unit as mentioned above. The duration-selective neurons described in the present report may contribute to the perception of auditory information in the time domain for periods within a segmental unit of approximately hundreds of milliseconds. The possibility that duration-selective neurons will be predominant components of higher auditory areas involved in complex sound perception should be investigated.

In conclusion, duration tuning has been described previously only at the midbrain level in amphibians and bats. The present finding of sensitivity to sound duration in at least one region of cat auditory cortex indicates that this form of neural tuning may be important for hearing in all vertebrates, and for processing of sound at multiple levels in the auditory pathway. The duration selectivity of the long-latency neurons is suggested to be the result of temporal integration, which includes both temporal summation and suppression during the latent period.

\section{REFERENCES}

Aitkin LM, Prain SM (1974) Medial geniculate body: unit responses in the awake cat. J Neurophysiol 37:512-521.

Andersen RA, Knight PL, Merzenich MM (1980) The thalamocortical and corticothalamic connections of AI, AII and the anterior auditory field (AAF) in the cat: evidence for two largely segregated systems of connections. J Comp Neurol 194:663-701.

Bordi F, LeDoux JE (1994) Response properties of single units in areas of rat auditory thalamus that project to the amygdala. I. Acoustic discharge patterns and frequency receptive fields. Exp Brain Res 98:261-274.

Calford MB (1983) The parcellation of the medial geniculate body of the cat defined by the auditory response properties of single units. J Neurosci 3:2350-2364.

Calford MB, Aitkin LM (1983) Ascending projections to the medial geniculate body of the cat: evidence for multiple, parallel auditory pathways through thalamus. J Neurosci 3:2365-2380.

Calford MB, Webster WR (1981) Auditory representation within principal division of cat medial geniculate body: an electrophysiological study. J Neurophysiol 45:1013-1028.

Casseday JH, Ehrlich D, Covey E (1994) Neural tuning for sound dura- 
tion: role of inhibitory mechanisms in the inferior colliculus. Science 264:847-850.

Dilollo V (1980) Temporal integration in visual memory. J Exp Psychol 109:75-97.

Feng AS, Hall JC, Goller DM (1990) Neural basis of sound pattern recognition in anurans. Prog Neurobiol 34:313-329.

Feng AS, Hall JC, Siddique S (1991) Coding of temporal parameters of complex sounds by frog auditory nerve fibers. J Neurophysiol 65:424-445.

Gawne TJ, Kjær TW, Richmond BJ (1996) Latency: another potential code for feature binding in striate cortex. J Neurophysiol 76:1356-1360.

Gerken GM, Bhat UK, Hutchison-Clutter M (1990) Auditory temporal integration and the power function model. J Acoust Soc Am 88:767-768

Goodman JC, Lee L, DeGroot J (1994) Development theories of speech perception: constraints from developmental data. In: The development of speech perception (Goodman JC, Nusbaum HC, eds), pp 3-33. Cambridge, MA: MIT.

Gooler DM, Feng AS (1992) Temporal coding in the frog auditory midbrain: the influence of duration and rise-fall time on the processing of complex amplitude-modulated stimuli. J Neurophysiol 67:1-22.

Green DM (1985) Temporal factors in psychoacoustics. In: Time resolution in auditory systems (Michelsen A, ed), pp 122-140. Berlin, New York: Springer.

Grothe B (1994) Interaction of excitation and inhibition in processing of pure tone and amplitude-modulated stimuli in the medial superior olive of the mustached bat. J Neurophysiol 71:706-721.

Hafter ER, Buell TN (1990) Restarting the adapted binaural system. J Acoust Soc Am 88:806-812.

He J (1997) Modulatory effects of regional cortical activation on the onset responses of the cat medial geniculate neurons. J Neurophysiol, in press.

He J, Ojima H, Hashikawa T, Jones EG (1994) Neuronal responses to noise-burst in and connection of anterodorsal region of cat primary auditory cortex. Soc Neurosci Abstr 20:324.

He J, Hashikawa T, Ojima H, Kinouchi Y (1996) Long-latent neurons in the cat dorsal auditory cortex in relation to temporal integration. Soc Neurosci Abstr 22:1068.

Hu B (1995) Cellular basis of temporal synaptic signaling: an in vitro electrophysiological study in rat auditory thalamus. J Physiol (Lond) 483:167-182.

Imig TJ, Reale RA (1980) Patterns of cortico-cortical connections related to tonotopic maps in cat auditory cortex. J Comp Neurol 192:293-332.

Irvine DRF (1980) Acoustic properties of neurons in posteromedial thalamus of cat. J Neurophysiol 43:395-408.

Langner G, Schreiner CE (1988) Periodicity coding in the inferior colliculus of the cat. I. Neuronal mechanisms. J Neurophysiol 60:1799-1822.

Lennartz RC, Weinberger NM (1992) Frequency selectivity is related to temporal processing in parallel thalamocortical auditory pathways. Brain Res 583:81-92.

Merzenich MM, Knight PL, Roth GL (1975) Representation of cochlea with primary auditory cortex in the cat. J Neurophysiol 38:231-249.

Merzenich MM, Schreiner C, Jenkins W, Wang X (1993) Neural mechanisms underlying temporal integration, segmentation, and input sequence representation: some implications for the origin of learning disabilities. Ann NY Acad Sci 682:1-22.

Mesulam MM (1976) The blue reaction product in horseradish peroxidase neurochemistry: incubation parameters and visibility. J Histochem Cytochem 24:1273-1280.

Middlebrooks JC, Xu L (1996) Information-bearing elements of spike trains in the cat's auditory cortex. Soc Neurosci Abstr 22:1068.
Middlebrooks JC, Zook JM (1983) Intrinsic organization of the cat's medial geniculate body identified by projections to binaural responsespecific bands in the primary auditory cortex. J Neurosci 3:203-224.

Middlebrooks JC, Clock AE, Xu L, Green DM (1994) A panoramic code for sound location by cortical neurons. Science 264:842-844.

Moore BCJ, Glasberg BR, Plack CJ, Biswas AK (1988) The shape of the ear's temporal window. J Acoust Soc Am 83:1102-1116.

Munson WA (1947) The growth of auditory sensation. J Acoust Soc Am 19:584-591.

Ojima H, He J (1994) Cortical convergence of horizontal axons originating from loci representing different frequencies in AI. Neurosci Res 19:S212.

Ojima H, Honda CN, Jones EG (1991) Patterns of axon collateralization of identified supragranular pyramidal neurons in the cat auditory cortex. Cereb Cortex 1:80-94.

Phillips DP, Semple MN, Calford MB, Kitzes LM (1994) Leveldependent representation of stimulus frequency in cat primary auditory cortex. Exp Brain Res 102:210-226.

Phillips DP, Semple MN, Kitzes LM (1995) Factors shaping the tone level sensitivity of single neurons in posterior field of cat auditory cortex. J Neurophysiol 73:674-686.

Pinheiro AD, Wu M, Jen PHS (1991) Encoding repetition rate and duration in the inferior colliculus of the big brown bat, Eptesicus fuscus. J Comp Physiol [A] 169:69-85.

Potter HD (1965) Patterns of acoustically evoked discharges of neurons in the mesencephalon of the bullfrog. J Neurophysiol 28:1155-1184.

Reale RA, Imig TJ (1980) Tonotopic organization in auditory cortex of the cat. J Comp Neurol 192:265-291.

Repp BH, Liberman AM, Eccardt T, Pesetsky D (1978) Perceptual integration of acoustic cues for stop, fricative, and affricate manner. J Exp Psychol Hum Percept Perform 4:621-637.

Rhode WS, Smith PH (1986) Encoding timing and intensity in the ventral cochlear of the cat. J Neurophysiol 56:261-286.

Semple MN, Kitzes LM (1993) Binaural processing of sound pressure level in cat primary auditory cortex: evidence for a representation based on absolute levels rather than interaural level differences. J Neurophysiol 69:449-461.

Spitzer MW, Semple MN (1993) Responses of inferior colliculus neurons to time-varying interaural phase disparity: effects of shifting the locus of virtual motion. J Neurophysiol 69:1245-1263.

Sutter ML, Schreiner CE (1991) Physiology and topography of neurons with multipeaked tuning curves in cat primary auditory cortex. J Neurophysiol 65:1207-1226.

Winer JA, Diamond IT, Raczkowski D (1977) Subdivisions of the auditory cortex of the cat: the retrograde transport of horseradish peroxidase to the medial geniculate body and posterior thalamic nuclei. J Comp Neurol 176:387-418.

Woolsey CN (1961) Organization of cortical auditory system. In: Sensory communication (Rosenblith WR, ed), pp 235-257. Cambridge, MA: MIT.

Woolsey CN (1964) Electrophysiological studies on thalamocortical relations in the auditory system. In: Unfinished tasks in the behavioral sciences (Abrams A, Garner HH, Tamam JEP, eds), pp 45-57. Baltimore: William \& Wilkins.

Zurita P, Villa AEP, de Ribaupierre Y, de Ribaupierre F, Rouiller EM (1994) Changes of single unit activity in the cat's auditory thalamus and cortex associated to different anesthetic conditions. Neurosci Res 19:303-316.

Zwislocki J (1960) Theory of temporal auditory summation. J Acoust Soc Am 32:1046-1060. 